\title{
Altered Sensory Experience Induces Targeted Rewiring of Local Excitatory Connections in Mature Neocortex
}

\author{
Claire E. J. Cheetham, Martin S. L. Hammond, Rachael McFarlane, and Gerald T. Finnerty \\ Medical Research Centre for Neurodegeneration Research, King's College London, London SE5 8AF, United Kingdom
}

Experience-dependent plasticity in adulthood is slower than during development. Previous experience can accelerate adult cortical plasticity. However, the contributions of functional synaptic changes and modifications in neuronal structure to the acceleration of adult cortical plasticity remain unclear. If structural remodeling was important then it should be exhibited by neuronal connections that have altered during plasticity. We trimmed rodents' whiskers to induce experience-dependent plasticity and reconstructed pairs of layer $2 / 3$ (L2/3) pyramidal neurons after electrophysiological recording. We reported recently that local excitatory connections strengthen without a change in synapse number in cortex with retained sensory input (spared) (Cheetham et al., 2007). Here, we show that strengthened connections are rewired. The rewiring involves remodeling of the axonal arbor of excitatory connections with only minor changes in postsynaptic dendritic trees. The axonal remodeling resulted in a greater length of presynaptic axon close to postsynaptic dendrites at existing local excitatory connections in spared cortex. In control cortex, the length of axon close to dendrite in unconnected pairs of L2/3 pyramidal neurons was similar to that in synaptically connected pairs of L2/3 pyramidal neurons. This finding suggests that the probability of forming a synapse and, therefore, establishing a connection, is not driven solely by the length of axon close to dendrite. The axonal remodeling that we describe is not associated with altered synapse number, but instead increases the number of sites where synapses could be formed between synaptically connected neurons with minimal structural changes. This enables rapid and cost-efficient rewiring of local excitatory connections when re-exposed to similarly altered sensory experience in adulthood.

Key words: somatosensory; axon; structural; reorganization; dendrite; memory

\section{Introduction}

The neocortex harbors orderly representations of the sensory periphery termed cortical maps (Kaas, 1987). These maps exhibit experience-dependent plasticity in adulthood, which is thought to be important for perceptual learning (Recanzone et al., 1992; Gilbert et al., 2001; Tsodyks and Gilbert, 2004; Dahmen and King, 2007). The pace of plastic change is slower in adulthood than during development (Buonomano and Merzenich, 1998; Fox, 2002; Karmarkar and Dan, 2006). However, perceptual learning (Hebb, 1949; Gibson, 1953; Guić-Robles et al., 1989; Harris et al., 1999, 2001; Knutsen et al., 2006) and reorganization of adult cortical maps (Hofer et al., 2006) occur more rapidly if animals have received similarly altered experience when younger.

Altering touch sensory input by trimming a subset of the whiskers of adult rodents results in expansion of the representation of spared (nontrimmed) whiskers in contralateral primary somatosensory cortex (Glazewski and Fox, 1996; Polley et al., 1999; Wallace and Fox, 1999;Lebedev et al., 2000; Maier et al., 2003). Reor-

\footnotetext{
Received June 27, 2008; revised July 29, 2008; accepted Aug. 2, 2008.

This work was supported by the Wellcome Trust and King's College Hospital Medical Research Trust (C.E.J.C.). G.T.F. is a Wellcome Trust Senior Fellow in the Clinical Sciences. We thank Frank Hirth, Beate Haege, Daniel Stahl, Graham Knott, Miguel Maravall, Karl Peter Giese, and members of the Finnerty laboratory for constructive comments.

Correspondence should be addressed to Gerald T. Finnerty, Medical Research Centre for Neurodegeneration Research, King's College London, Institute of Psychiatry, De Crespigny Park, London SE5 8AF, UK. E-mail: g.finnerty@iop.kcl.ac.uk.

DOI:10.1523/JNEUROSCI.2974-08.2008

Copyright $\odot 2008$ Society for Neuroscience $\quad$ 0270-6474/08/289249-12\$15.00/0
}

ganization is greatest in layer 2/3 (L2/3) (Diamond et al., 1994). The underlying cellular mechanisms have not been fully elucidated, but are probably a consequence of the increased firing in spared primary somatosensory cortex (SI) of freely moving animals that develops immediately after whisker trimming (Kelly et al., 1999). This is followed by strengthening of excitatory connections between neighboring pyramidal neurons in L2/3 of spared cortex of mature animals (Cheetham et al., 2007).

Increases in the strength of local excitatory connection in L2/3 of spared cortex probably contribute to reorganization of the cortical representation of spared whiskers (Cheetham et al., 2007). However, alterations in synaptic strength, in isolation, do not provide a compelling explanation for the acceleration of adult plasticity attributable to previous experience. Persistent structural changes that enable experience-dependent plasticity may also be required (Hebb, 1949; Greenough, 1984), but their locus and nature remain unclear. Adult pyramidal neurons have the capacity to undergo large-scale remodeling. However, both axonal (Darian-Smith and Gilbert, 1994; Florence et al., 1998; Kossut, 1998) and dendritic (Hickmott and Steen, 2005; Tailby et al., 2005) remodeling are most prominent after sensory deafferentation. The evidence that large-scale structural changes occur after neocortical experience-dependent plasticity in an intact adult nervous system is mixed (Uylings et al., 1978; Chklovskii et al., 2004).

If structural changes in neurons were important in accelerating adult perceptual learning and cortical map reorganization, 
then it should be possible to detect those changes in connections that have undergone functional alterations during experiencedependent plasticity. Here, we show that there is rewiring of local excitatory connections that have strengthened during experience-dependent plasticity. The rewiring involves axonal remodeling, which increases the length of presynaptic axon close to postsynaptic dendrites of synaptically connected L2/3 pyramidal neurons. Synapse number at local excitatory connections is not increased (Cheetham et al., 2007). Nevertheless, the axonal remodeling can explain how previous experience accelerates experience-dependent plasticity of neocortical microcircuits and could, thereby, contribute to enhanced perceptual learning in adulthood.

\section{Materials and Methods}

Whisker trimming. All procedures were performed in accordance with the United Kingdom Animals (Scientific Procedures) Act of 1986. We trimmed bilaterally the dorsal three rows (A-C) of whiskers and the $\alpha, \beta$, and $\gamma$ straddler whiskers or the ventral two (D, E) rows of whiskers and the $\gamma$ and $\delta$ straddler whiskers flush with the skin every day. Whisker trimming or sham trimming started at postnatal day 19 (P19), which is after the L2/3 whisker map has developed (Stern et al., 2001), and continued for 13-41 d.

Brain slice preparation and recording. Brain slice preparation and recording have been described previously (Cheetham et al., 2007). Briefly, brain slices were cut $\left(65^{\circ}\right.$ to the midline) across the whisker barrel rows. Bright-field illumination was used to identify brain slices containing whisker barrels. Neurons in layer $2 / 3$ of the $C$ or D barrel columns were visualized using infrared differential interference contrast. Patch-clamp recordings were made from pairs of pyramidal neurons in $\mathrm{L} 2 / 3$ of the $\mathrm{C}$ or D barrel columns at $36-37^{\circ} \mathrm{C}$. Recording pipettes (4-7 $\mathrm{M} \Omega$ ) contained (in mM) $130 \mathrm{KMeSO}_{4}, 8 \mathrm{NaCl}, 2 \mathrm{KH}_{2} \mathrm{PO}_{4}, 2$ D-glucose, $10 \mathrm{HEPES}$, 1 Alexa Fluor 488 (AF488) or 1 Alexa Fluor 568 (AF568) (Invitrogen), and $3-5 \mathrm{mg} / \mathrm{ml}$ biocytin. A pair of neurons was referred to as "connected" when both cells were recorded in whole-cell mode and action potentials in one neuron evoked EPSPs in the other neuron (see Fig. $4 \mathrm{~B}$ ). Connections were termed "reciprocal" when the connection was bidirectional (Cheetham et al., 2007).

Confocal microscopy. Slices were fixed in either $4 \%$ paraformaldehyde for $30 \mathrm{~min}$ or $2 \%$ paraformaldehyde $/ 0.1 \%$ glutaraldehyde for two $\mathrm{h}$ at $4^{\circ} \mathrm{C}$ after electrophysiological recording was completed, mounted with either Gel/Mount (Biomeda) or phosphate buffered saline and imaged on a Zeiss LSM510 META confocal microscope. Low-resolution images of neurons were collected with a $20 \times$ objective for measurement of radial widths of apical and basal dendritic trees. Higher-resolution images were obtained with a $63 \times, 1.2$ numerical aperture C-Apochromat waterimmersion objective. Pinhole diameters (maximum, 1 Airy unit) were adjusted to give identical optical slice thicknesses for AF488 and AF568 tracks. Medium resolution $z$-stacks $(\leq 120 \mu \mathrm{m})$ were obtained for measurement of dendritic path length and spine counts using a voxel size of $0.14 \times 0.14 \times 0.43 \mu \mathrm{m}$. Regions where presynaptic axons were close to postsynaptic dendrites were re-imaged at high resolution (voxel, $0.07 \times$ $0.07 \times 0.2 \mu \mathrm{m}$ ). Data sets were deconvolved with AutoDeblur (AutoQuant) before imaging with Imaris (Bitplane). Synapse counts from five of the nine connected pairs of $\mathrm{L} 2 / 3$ pyramidal neurons in control cortex and six of the 11 connected pairs of L2/3 pyramidal neurons in spared cortex were reported recently (Cheetham et al., 2007).

Dendritic structure. Dendritic path lengths were measured in three dimensions along the length of the dendrite using Measurement Pro running under Imaris (Bitplane). Basal dendrites were defined to start when their shaft diameters were $\leq 2.0 \mu \mathrm{m}$ and the apical main stem was defined to start when its shaft diameter was $\leq 4.0 \mu \mathrm{m}$. Tips of dendrites were defined to be natural ends if the dendrite was not cut and did not "fade out." L2/3 pyramidal neurons used for dendritic length analysis had a minimum of 16 basal dendrite tips and 16 apical (oblique and terminal arbor) dendrite tips. Dendrograms were generated from dendritic path length measurements (see Fig. $1 A, B$ ). Dendritic branching was measured as the number of dendrite intersections with Sholl shells that were at constant dendrite path lengths from the soma (see Fig. $1 B$ ). The radii of Sholl shells increased in $10 \mu \mathrm{m}$ increments. Statistical analysis of the number of dendritic intersections was restricted to a path length of $270 \mu \mathrm{m}$ from the soma, which comprises all dendrites except for the furthest part of the terminal arbor (supplemental Fig. 1, available at www.jneurosci.org as supplemental material), to ensure that the number of dendritic intersections per Sholl shell fulfilled the constant variance assumption of the Gaussian family. The terminal arbor was defined as the apical dendrite segments formed after the apical main stem has divided into, typically, two branches of similar diameter. Radial widths of basal and apical dendrites were measured as the distance of the furthest dendritic tip from a line that was perpendicular to the pia and passed through the center of the soma.

Spine densities were measured by scrolling up and down through a dendrite and counting all spines in $10 \mu \mathrm{m}$ sections at measured path lengths from the start of the dendrite. Peak spine density on basal dendrites was the spine density measured $50-70 \mu \mathrm{m}$ from the soma on five basal dendrites per neuron. Apical spine density was measured by counting spines in $10 \mu \mathrm{m}$ sections along the apical main stem beginning at 40 $\mu \mathrm{m}$ from the soma and extending to $140 \mu \mathrm{m}$ from the soma to encompass the region of peak apical spine density. Dendritic protrusions characterized as filopodia (thin neck $>3 \mu \mathrm{m}$ in length and no head) were not included in spine measurements.

Axonal varicosity density. A simple criterion for the presence of an axonal varicosity would be expansion of the axon with respect to the adjacent axonal shaft. The difficulty with implementing this criterion for confocal images is that image resolution in the $z$-axis is worse than in the $x-y$ plane, making it possible that varicosities that predominantly expand along the $z$-axis can be missed. Therefore, we developed two criteria to identify axonal varicosities. The first criterion comprised a "diameter ratio," which was the maximum diameter of a varicosity relative to the immediately adjacent axonal shaft measured in the higher-resolution $x-y$ plane of the confocal optical section. The second criterion comprised an "intensity ratio," which was the fluorescence intensity of a potential varicosity relative to the immediately adjacent axonal shaft. This criterion uses the fact that small increases in axonal width in the $z$-axis will increase the fluorescence signal from a putative varicosity because optical sectioning is not perfect. All varicosity measurements were made on highresolution confocal images after deconvolution. The fluorescence signal within the axon and the diameter of the axon in single $z$-slice images containing a nonsaturated axonal varicosity and adjacent axonal shaft $(n=40)$ were measured using Image J 1.36 (http://rsb.info.nih.gov/ij/). Fluorescence intensity measurements were the mean of 10 contiguous pixels in the same image section (in-plane area, $0.049 \mu \mathrm{m}^{2}$ ) in the center of the axonal varicosity or in the adjacent axonal shaft. The distribution of the intensity ratio for putative en passant varicosities was compared with the distribution of regions of the axon where fluorescence signal increased without an expansion of the axon diameter $(n=40)$. We found that both a diameter ratio $\geq 1.25$ and an intensity ratio $\geq 1.30$ were required to identify a varicosity reliably. Terminaux and en passant varicosities were counted on lengths of axon that included regions of proximity and extended $<20 \mu \mathrm{m}$ on either side of the region of proximity (RoP) to increase the length of measured axon.

Statistics. Dendritic and axonal data were collected using a prospective experimental design and a random sample of neurons. Target sample sizes were decided in advance. Data with a normal distribution are described by their mean \pm SEM whereas data with non-normal distributions are expressed as median and interquartile range (IQR). Results for data comprising multiple measurements on single neurons are reported as the average of the mean or median value for each neuron and are termed grand means or grand medians respectively.

We performed statistical modeling under the generalized linear model framework (McCullagh and Nelder, 1989) with extension to generalized additive models (Hastie and Tibshirani, 1990) and generalized estimating equations (Zeger and Liang, 1986; Liang and Zeger, 1986) using the "stats," "mgcv," "nlme," "MASS," and "gee" packages implemented in R (R Project for Statistical Computing, http://www.r-project.org/). Generalized additive models were used when the response variable was a func- 


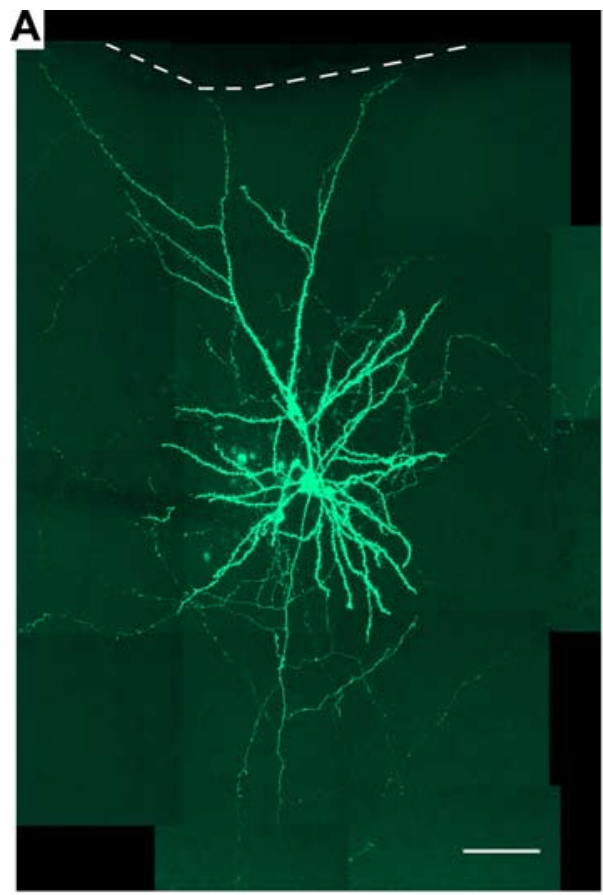

B

C
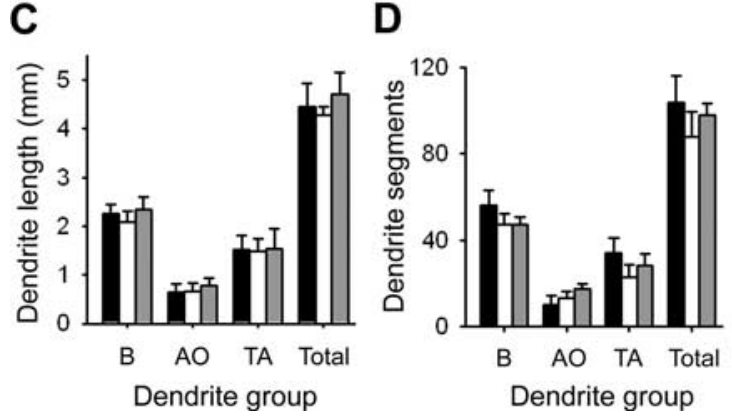

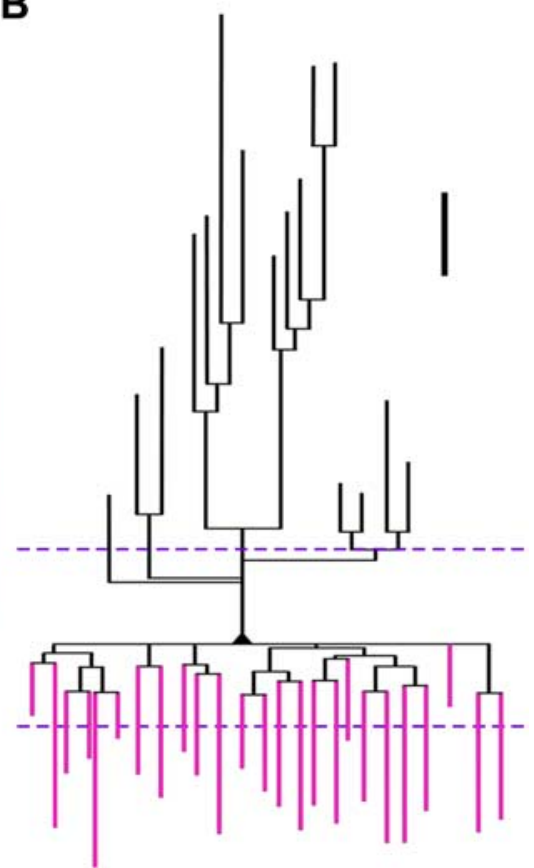

E

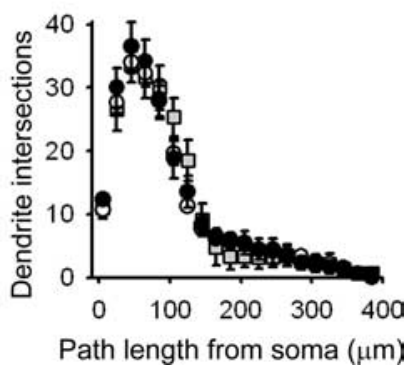

Figure 1. Dendritic morphology is not markedly altered by whisker trimming. $A$, Montage of maximum intensity projections of confocal $z$-stacks of the presynaptic neuron from a pair of synaptically connected $L 2 / 3$ pyramidal neurons in control cortex. The white dashed line denotes the pia. Scale bar, $50 \mu \mathrm{m}$. $\boldsymbol{B}$, Dendrogram of the L2/3 pyramidal neuron in $\boldsymbol{A}$. Segment lengths are drawn to scale along the axis denoted by the scale bar $(50 \mu \mathrm{m})$. Basal dendrites are drawn in black up to terminal branch points with terminal segments shown in magenta. The horizontal dashed lines denote Sholl shells which are at $50 \mu \mathrm{m}$ from the origin of the apical main stem (top dashed line) or basal dendrites (bottom dashed line). C, Mean dendritic lengths of basal (B), apical oblique ( $A 0)$, and terminal arbor (TA) branches and mean total dendritic length of $L 2 / 3$ pyramidal neurons in spared (black), deprived (white), and control (gray) cortex. Data in $\boldsymbol{C}-\boldsymbol{E}$ are based on six spared, six deprived, and six control neurons. Error bars denote SEM. D, Mean number of dendritic segments on basal, apical oblique, and terminal arbor branches, and the total number of dendritic segments for L2/3 pyramidal neurons in spared (black), deprived (white), and control (gray) cortex. E, Sholl analysis using dendritic path length and $20 \mu \mathrm{m}$ shells centered on the soma for neurons in control (gray squares), spared (black circles), and deprived (white circles) cortex.

Table 1. Dendritic morphology of L2/3 pyramidal neurons after whisker deprivation

\begin{tabular}{llll}
\hline & Control & Deprived & Spared \\
\hline Age (postnatal days) & $45(34-45)$ & $41(33-45)$ & $47.5(46-49)$ \\
Total dendritic path length $(\mu \mathrm{m})$ & $4715 \pm 436$ & $4283 \pm 173$ & $4446 \pm 481$ \\
Dendritic segments per neuron & $47 \pm 4$ & $47 \pm 5$ & $56 \pm 7$ \\
Basal dendritic trees per neuron & $5(4.75-6)$ & $5(5-5)$ & $5.5(5-6)$ \\
Basal dendrite tips per neuron & $28 \pm 2$ & $25 \pm 2$ & $28 \pm 3$ \\
Basal dendrite tips per tree & $5(4-8)$ & $5(3.25-7)$ & $6(3-7.25)$ \\
Radial spread of basal dendrites $(\mu \mathrm{m})$ & $279 \pm 18$ & $268 \pm 13$ & $254 \pm 9$ \\
Radial spread of apical dendrites $(\mu \mathrm{m})$ & $210(181-248)$ & $267(210-299)$ & $229(205-246)$ \\
\hline
\end{tabular}

Data are given as mean \pm SEM if normally distributed or median (interquartile range) if not normally distributed. The duration of deprivation is age minus $19 \mathrm{~d}$. Deprivation did not affect total dendritic path length $\left(p=0.734, F_{(2,15)}=0.32, n=6\right.$ per group, one-way ANOVA), the number of dendritic segments $\left(p=0.400, F_{(2,15)}=0.97, n=6\right.$ per group, one-way ANOVA), the number of basal dendritic trees per neuron $(p=0.534, H=1.26, \mathrm{df}=2, n=9$ control, 8 spared and 8 deprived, one-way ANOVA on ranks), the total number of basal dendrite tips $\left(p=0.612, F_{(2,22)}=0.50, n=9\right.$ control, 8 spared and 8 deprived, one-way ANOVA), the number of dendritic tips per basal dendrite tree (Table 2 , model 1 ), the radial spread of basal dendrites $\left(p=0.441, F_{(2,15)}=0.87, n=\right.$ 6 neurons per group, one-way ANOVA), or the radial spread of apical dendrites ( $p=0.417, H=1.75, \mathrm{df}=2$, one-way ANOVA on ranks).

tion of one or more explanatory variables. Generalized estimating equations were used to account for correlations in the data that are likely to occur when cluster sampling (Cochran, 1977 ) is used, e.g., when multiple measurements are taken from single neurons. Models were of the general form $g[E(Y)]=\alpha+f\left[Z_{i}\right]+$ $\beta\left(Z_{j}\right)+\gamma\left(Z_{k}\right)+\delta\left(Z_{j} \times Z_{k}\right) \ldots$, where $g$ is the link function; $E(Y)$ is the expected value of the response variable, $Y ; f\left[Z_{i}\right]$ is an explanatory variable that is a smooth function of $Z_{i} ; Z_{j}, Z_{k}$, and $\left(Z_{j} \times Z_{k}\right)$ are explanatory variables with $\left(Z_{j}\right.$ $\times Z_{k}$ ) denoting interaction between $Z_{j}$ and $Z_{k}$; and $\alpha, \beta, \gamma$, and $\delta$ are parameters (coefficients) of the model. Deprivation status was modeled with two dummy explanatory variables in which SP (spared $=1$, otherwise 0 ) denoted L2/3 pyramidal neurons in spared cortex and DEP (deprived $=1$, otherwise 0 ) referred to L2/3 pyramidal neurons in deprived cortex so that control cortex data are encoded (SP, DEP) by $(0,0)$, spared cortex data are encoded by $(1$, $0)$, and deprived cortex data are encoded by $(0$, 1). The duration of deprivation, which equals age minus $19 \mathrm{~d}$, was modeled as the interaction between deprivation status and age. Unstructured working correlation matrices were used for all models based on generalized estimating equations. Either minimization of Akaike's Information Criterion or an analysis of deviance was used on nested models to find the best model for the data. If compared models had the same number of explanatory variables and Akaike's Information Criterion could not be calculated, then the best model was taken to be the one that maximized the explained deviance. Two-tailed $p$ values for results from models based on generalized estimating equations were calculated using the robust (sandwich) estimate of variance. For clarity of presentation, the modeling framework, link function, error distribution family, and results for all explanatory variables with associated $p$ values (two-tailed) are tabulated in Table 2. We use the term "predicted" to refer to results predicted from the statistical models by interpolation.

\section{Results}

\section{Dendritic structure}

We first investigated whether experiencedependent plasticity was accompanied by structural changes in the dendrites of $\mathrm{L} 2 / 3$ pyramidal neurons in SI. Sensory input to SI was altered by trimming either the dorsal three rows $(\mathrm{A}-\mathrm{C})$ or the ventral two rows (D, E) of rats' whiskers (see Materials and Methods). Brain slices were prepared and pyramidal neurons in L2/3 of C or D barrel columns were filled with fluorescent dye during electrophysiological recording, reconstructed in three dimensions (Fig. $1 A$ ), and their morphology characterized with simple metrics (Table 1). Deprivation did not affect the total dendritic path length (Fig. $1 B, C$ ), number of dendritic segments (Fig. 1D), number of basal dendritic trees, number of dendritic tips per 
Table 2. Statistical models

\begin{tabular}{|c|c|c|c|c|}
\hline $\begin{array}{l}\text { Model number, response variable, framework, } \\
\text { link function, family }\end{array}$ & Explanatory variable & Coefficient & $\begin{array}{l}\text { Statistic ( } n \text { for } z \text { statistic or edf } \\
\text { for } t \text { statistic) }\end{array}$ & $p$ \\
\hline \multirow{5}{*}{$\begin{array}{l}\text { 1, number of tips per basal tree, GEE, log link } \\
\text { (quasi, variance function = mean) }\end{array}$} & Intercept & $2.15 \pm 0.39$ & $z=5.54(110)$ & $<0.001$ \\
\hline & $S P$ & $0.037 \pm 0.095$ & $z=0.39(110)$ & 0.693 \\
\hline & DEP & $-0.054 \pm 0.103$ & $z=-0.52(110)$ & 0.600 \\
\hline & Age & $0.006 \pm 0.007$ & $z=0.77(110)$ & 0.441 \\
\hline & Number basal trees & $-0.12 \pm 0.03$ & $z=-4.63(110)$ & $<0.001$ \\
\hline \multirow{5}{*}{$\begin{array}{l}\text { 2, dendrite intersections, GAM, identity link, } \\
\text { Gaussian }\end{array}$} & Intercept & $8.4 \pm 2.3$ & $t=3.57(473)$ & $<0.001$ \\
\hline & $f$ (path length) & $\mathrm{N} / \mathrm{A}$ & $F=260($ edf $=7.8)$ & $<0.001$ \\
\hline & SP & $0.92 \pm 0.63$ & $t=1.46(473)$ & 0.146 \\
\hline & DEP & $0.60 \pm 0.67$ & $t=0.90(473)$ & 0.371 \\
\hline & Age & $0.15 \pm 0.05$ & $t=2.92(473)$ & 0.004 \\
\hline \multirow{5}{*}{$\begin{array}{l}\text { 3, basal terminal segment path length, GEE, } \\
\text { identity link, Gaussian }\end{array}$} & Intercept & $131.4 \pm 11.6$ & $z=11.4(315)$ & $<0.001$ \\
\hline & SP & $0.01 \pm 4.7$ & $z=0.002(89)$ & 0.999 \\
\hline & DEP & $-7.1 \pm 3.4$ & $z=-2.08(106)$ & 0.037 \\
\hline & Branch order & $-8.3 \pm 1.4$ & $z=-6.04(315)$ & $<0.001$ \\
\hline & Number of basal tips & $-0.32 \pm 0.32$ & $z=-1.03(315)$ & 0.301 \\
\hline \multirow{5}{*}{$\begin{array}{l}\text { 4, basal terminal segment path length, GEE, } \\
\text { identity link, Gaussian (interaction model) }\end{array}$} & Intercept & $130.4 \pm 11.4$ & $z=11.5(315)$ & $<0.001$ \\
\hline & $S P \times$ age & $0.04 \pm 0.12$ & $z=0.36(89)$ & 0.719 \\
\hline & DEP $\times$ age & $-0.16 \pm 0.08$ & $z=-1.99(106)$ & 0.047 \\
\hline & Branch order & $-8.1 \pm 1.4$ & $z=-5.81(315)$ & $<0.001$ \\
\hline & Number of basal tips & $-0.33 \pm 0.32$ & $z=-1.03(315)$ & 0.303 \\
\hline \multirow{6}{*}{$\begin{array}{l}\text { 5, path length to terminal branch point, GEE, log } \\
\text { link (quasi, variance function = mean) }\end{array}$} & Intercept & $2.63 \pm 0.28$ & $z=9.3(315)$ & $<0.001$ \\
\hline & SP & $-0.13 \pm 0.06$ & $z=-2.38(89)$ & 0.017 \\
\hline & DEP & $-0.12 \pm 0.06$ & $z=-2.12(106)$ & 0.033 \\
\hline & Branch order & $0.24 \pm 0.02$ & $z=-14.2(315)$ & $<0.001$ \\
\hline & Number of basal trees & $-0.12 \pm 0.03$ & $z=-4.11(315)$ & $<0.001$ \\
\hline & Age & $0.013 \pm 0.006$ & $z=2.15(315)$ & 0.032 \\
\hline \multirow{4}{*}{$\begin{array}{l}\text { 6, peak basal spine density, GEE, identity link, } \\
\text { Gaussian }\end{array}$} & Intercept & $1.97 \pm 0.18$ & $z=10.9(120)$ & $<0.001$ \\
\hline & SP & $-0.12 \pm 0.07$ & $z=-1.65(40)$ & 0.099 \\
\hline & DEP & $-0.25 \pm 0.07$ & $z=-3.71(40)$ & $<0.001$ \\
\hline & Age & $-0.012 \pm 0.003$ & $z=-3.42(120)$ & $<0.001$ \\
\hline \multirow{4}{*}{$\begin{array}{l}\text { 7, peak basal spine density, GEE, identity link, } \\
\text { Gaussian (interaction model) }\end{array}$} & Intercept & $1.88 \pm 0.17$ & $z=11.3(120)$ & $<0.001$ \\
\hline & $(\mathrm{SP} \times$ age $)$ & $-0.003 \pm 0.002$ & $z=-1.96(40)$ & 0.050 \\
\hline & (DEP $\times$ age $)$ & $-0.006 \pm 0.001$ & $z=-4.09(40)$ & $<0.001$ \\
\hline & Age & $-0.010 \pm 0.003$ & $z=-2.97(120)$ & 0.003 \\
\hline \multirow{5}{*}{$\begin{array}{l}\text { 8, apical spine density, GAM, identity link, } \\
\text { Gaussian }\end{array}$} & Intercept & $1.61 \pm 0.16$ & $t=10.3(253)$ & $<0.001$ \\
\hline & $f$ (path length) & NA & $F=1.49(\mathrm{edf}=2.8)$ & 0.182 \\
\hline & SP & $0.013 \pm 0.055$ & $t=0.23(253)$ & 0.817 \\
\hline & DEP & $0.001 \pm 0.059$ & $t=0.02(253)$ & 0.981 \\
\hline & Age & $-0.006 \pm 0.003$ & $t=1.85(253)$ & 0.066 \\
\hline \multirow{6}{*}{$\begin{array}{l}\text { 9, total axonal length in regions of proximity, } \\
\text { GLM, log link (quasi, variance function = } \\
\text { mean }^{2} \text { ) }\end{array}$} & Intercept & $3.03 \pm 0.87$ & $t=3.46(41)$ & 0.001 \\
\hline & $(\mathrm{SP} \times$ conn $)$ & $1.12 \pm 0.37$ & $t=3.04(41)$ & 0.004 \\
\hline & (SP $\times$ unconn) & $-0.27 \pm 0.38$ & $t=-0.71(41)$ & 0.482 \\
\hline & DEP & $0.68 \pm 0.47$ & $t=-1.43(41)$ & 0.161 \\
\hline & Age & $0.01 \pm 0.02$ & $t=0.74(41)$ & 0.466 \\
\hline & Intersomatic distance & $0.002 \pm 0.005$ & $t=-0.45(41)$ & 0.656 \\
\hline \multirow{4}{*}{$\begin{array}{l}\text { 10, axonal varicosity density, GEE, inverse link, } \\
\text { gamma family }\end{array}$} & Intercept & $1.09 \pm 0.13$ & $z=8.37(168)$ & $<0.001$ \\
\hline & $S P$ & $-0.19 \pm 0.07$ & $z=-2.63(126)$ & 0.008 \\
\hline & Basal & $0.09 \pm 0.04$ & $z=2.27(103)$ & 0.023 \\
\hline & Age & $0.003 \pm 0.003$ & $z=1.08(168)$ & 0.281 \\
\hline \multirow{5}{*}{$\begin{array}{l}\text { 11, proportion of terminaux varicosities, GEE, } \\
\text { identity link, Gaussian family }\end{array}$} & Intercept & $0.101 \pm 0.023$ & $z=4.46(98)$ & $<0.001$ \\
\hline & $(\mathrm{SP} \times$ conn $)$ & $0.025 \pm 0.012$ & $z=2.07(52)$ & 0.038 \\
\hline & (SP $\times$ unconn) & $0.053 \pm 0.013$ & $z=4.25(11)$ & $<0.001$ \\
\hline & (CNTRL $\times$ unconn) & $-0.002 \pm 0.013$ & $z=-0.13(20)$ & 0.889 \\
\hline & Age & $0.0006 \pm 0.0005$ & $z=-1.25(98)$ & 0.212 \\
\hline
\end{tabular}

Statistical models were classified as generalized linear model (GLM), generalized additive model (GAM), or generalized estimating equations (GEE). Model variables were as follows: number of basal trees, number of basal trees originating from the L2/3 pyramidal neuron soma; intersections, number of intersections with a Sholl shell; path length, path length from the soma; CNTRL, control cortex; age, age in postnatal days; branch order, order of the terminal dendritic branch; number of basal tips, total number of basal dendritic endings for the L2/3 pyramidal neuron; path length to terminal branch point, path length to the point where the terminal segment originates; peak basal spine density, spine count per $\mu \mathrm{m}$ on basal dendrites $50-70 \mu \mathrm{m}$ from the soma; apical spine density, spine count per micrometer on the apical main stem dendrite; number of basal trees, number of basal dendritic trees on an $\mathrm{L} 2 / 3$ pyramidal neuron; conn, presence of a synaptic connection between the axon of the presynaptic pyramidal neuron with the postsynaptic pyramidal neuron that has been demonstrated electrophysiologically; unconn, electrophysiological testing did not demonstrate evidence for a synaptic connection between the axon of the putative presynaptic pyramidal neuron with the postsynaptic pyramidal neuron; intersomatic distance, distance between the somata of two pyramidal neurons; basal, basal dendrite in RoP; edf, estimated degrees of freedom for explanatory variables that are used as functions in generalized additive models; NA, not applicable.

basal tree [Tables 1, 2 (model 1)], or the radial spread of either basal dendrites or apical dendrites (Table 1).

The density of dendritic branches was measured by counting the number of dendritic intersections with Sholl shells (Fig. $1 E$; supplemental Fig. 1, available at www.jneurosci.org as supplemental material). Data from six control, six spared and six de- prived L2/3 pyramidal neurons were analyzed with a statistical model that used path length from the soma, deprivation status and age as explanatory variables (Table 2, model 2). Whisker trimming did not affect dendrite branch density in spared ( $p=$ 0.146 ) or deprived cortex ( $p=0.371)$ compared with control cortex. However, dendrite branch density increased slowly with 
age ( $p=0.004)$ (supplemental text, supplemental Fig. 2, available at www.jneurosci.org as supplemental material).

\section{Remodeling of basal dendrites}

Our initial studies showed no evidence of large-scale changes in the dendrites of L2/3 pyramidal neurons. We reasoned that we would be better able to detect small amplitude changes in dendritic length caused by whisker trimming if we restricted analysis to basal dendrites with natural ends (see Materials and Methods). The path length of naturally ending terminal segments (terminal segment path length: control, $96 \pm 2 \mu \mathrm{m}, n=120$ dendrite tips from 9 neurons; spared, $88 \pm 3 \mu \mathrm{m}, n=89$ dendrite tips from 8 neurons; deprived, $86 \pm 3 \mu \mathrm{m}, n=106$ dendrite tips from 8 neurons) was investigated initially with age as an explanatory variable. However, age had no effect (supplemental text, supplemental Fig. $3 A$, available at www.jneurosci.org as supplemental material), suggesting that the length of basal terminal segments of control L2/3 pyramidal neurons did not change over our study period. Accordingly, analysis of the path length of basal terminal segments was restricted to the effects of deprivation status, branch order of the terminal segment and total number of basal dendrite tips per neuron (Table 2, model 3; supplemental Fig. $3 B, C$, available at www.jneurosci.org as supplemental material). The branch order of the terminal segment had a pronounced effect on path length of the terminal segment; the predicted decrease in terminal segment path length was $8.3 \mu \mathrm{m}$ for a unit increase in branch order $(p<0.001)$ (supplemental Fig. $3 B$, available at www.jneurosci.org as supplemental material). The length of basal terminal segments in spared cortex $(p=0.999)$ was similar to controls, but basal terminal segments were shorter in deprived cortex $(p=0.037$; model 3 predicted a $7.1 \mu \mathrm{m}$ decrease). The results of this model can be interpreted as suggesting that this effect of whisker trimming in deprived cortex had developed before P33, i.e., when measurements were first made, and persisted throughout the deprivation period.

The path length of basal terminal segments was reanalyzed with a different statistical model using interaction terms to address whether the effect of deprivation increased with the duration of deprivation (Table 2, model 4) (see Materials and Methods). We found a progressive reduction in the length of basal terminal segments in deprived cortex $(p=0.047)$, but not in spared cortex $(p=0.719)$ compared with controls. The predicted decrease in the length of basal terminal segments in deprived cortex between P33 and P49 was $2.6 \mu \mathrm{m}$, which is less than the $7.1 \mu \mathrm{m}$ shortening predicted by model 3 . We concluded that there was minor, but statistically significant, shortening of basal terminal segments of L2/3 pyramidal neurons in deprived cortex after whisker trimming. Together, the results may be interpreted as signifying that there was a decrease in basal terminal segment length before $\mathrm{P} 33$, which progressed further over our recording period.

Trimming whiskers during development slows the physiological, age-related increase in distance from the soma to the terminal branch points of basal dendrites on L2/3 pyramidal neurons (Fig. $1 B$ ) (Maravall et al., 2004). However, this effect is lost if the whisker trimming protocol starts at P15 and is brief, e.g., $5 \mathrm{~d}$ (Maravall et al., 2004). We explored whether prolonged whisker trimming starting at P19 could evoke structural changes at the proximal part of the basal dendritic tree (Table 2, model 5; supplemental text, available at www.jneurosci.org as supplemental material). Path length to the terminal branch point [grand median (IQR), $25 \mu \mathrm{m}(17-33 \mu \mathrm{m}) ; n=315]$ increased with branch order of the terminal segment $(p<0.001)$ (supplemental Fig.
$3 D$, available at www.jneurosci.org as supplemental material) and age $(p=0.032)$ (supplemental Fig. 3E, available at www. jneurosci.org as supplemental material) and decreased with the number of basal trees on an L2/3 pyramidal neuron $(p<0.001)$ (supplemental Fig. $3 F$, available at www.jneurosci.org as supplemental material). Whisker trimming reduced the age-related increase in path length to the terminal branch point in both spared ( $p=0.017)$ and deprived cortex ( $p=0.033)$ (supplemental Fig. $3 E$, available at www.jneurosci.org as supplemental material). We concluded that dendritic trees of L2/3 pyramidal neurons are not fixed after P15, but that there is low-level physiological reorganization of the proximal basal dendritic tree during the second postnatal month.

\section{Spine density on basal dendrites}

We next investigated whether whisker trimming and age altered basal dendrite spine density (Fig. $2 A-D$ ). Spine density altered with path length from the soma; it was low in the proximal part of the dendritic tree of $\mathrm{L} 2 / 3$ pyramidal neurons, increased rapidly to a peak $\sim 40-100 \mu \mathrm{m}$ from the soma, depending on the dendrite subgroup, and then slowly declined with increasing distance from the soma (Fig. 2A-D) (Larkman, 1991). We measured peak basal spine density (Materials and Methods) to reduce the variability introduced by path length from the soma (peak basal spine density per neuron: control, $1.45 \pm 0.06$ spines $\cdot \mu \mathrm{m}^{-1}$ from 9 neurons; spared, $1.38 \pm 0.08$ spines $\cdot \mu \mathrm{m}^{-1}$ from 8 neurons; deprived, $1.29 \pm 0.04$ spines $\cdot \mu \mathrm{m}^{-1}$ from 8 neurons). Peak basal dendrite spine density was modeled with age and deprivation status as explanatory variables (Table 2, model 6; supplemental text, available at www.jneurosci.org as supplemental material). Spine density decreased with age $(p<0.001)$ (supplemental Fig. 4 , available at www.jneurosci.org as supplemental material). The effect of deprivation status varied with cortical location: spine density was reduced in deprived cortex $(p<0.001)$, but did not change in spared cortex ( $p=0.099)$ (supplemental Fig. 4, available at www.jneurosci.org as supplemental material). The predicted decrease in spine density (50-70 $\mu \mathrm{m}$ from the soma) on basal dendrites over the period P33 to P49 was as follows: controls, $1.57-1.38$ spines $\cdot \mu \mathrm{m}^{-1}$; spared, $1.45-1.26$ spines $\cdot \mu \mathrm{m}^{-1}$; and deprived, $1.32-1.13$ spines $\cdot \mu \mathrm{m}^{-1}$.

We reanalyzed the data with a second model using interaction terms to determine whether the effect of deprivation increased with the duration of deprivation (Table 2, model 7) (see Materials and Methods). There was a progressive decrease in spine density in deprived cortex attributable to the duration of deprivation $(p<0.001)$. There was a tendency for a progressive decrease in basal dendrite spine density with the duration of deprivation in spared cortex $(p=0.050)$. However, the effects of duration of deprivation in spared cortex should be interpreted with caution. First, age alone affected spine density (model 6) $(p<0.001)$. Second, the effects of age, deprivation status, and an interaction between age and deprivation status could not be separated because of collinearity of these variables. Together, the results of models 6 and 7 suggest that there was a decrease in basal dendrite spine density attributable to age alone. A further reduction in basal dendrite spine density attributable to whisker trimming is superimposed on the age-related decline of spine density in deprived cortex. In contrast, there was no marked change in basal dendrite spine density attributable to whisker trimming in spared cortex. 
A

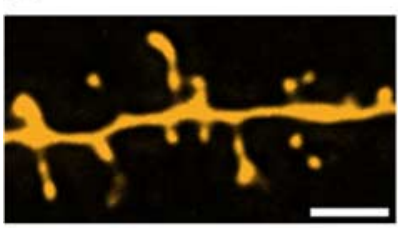

B

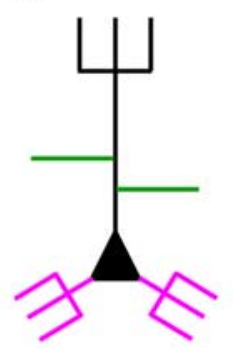

C

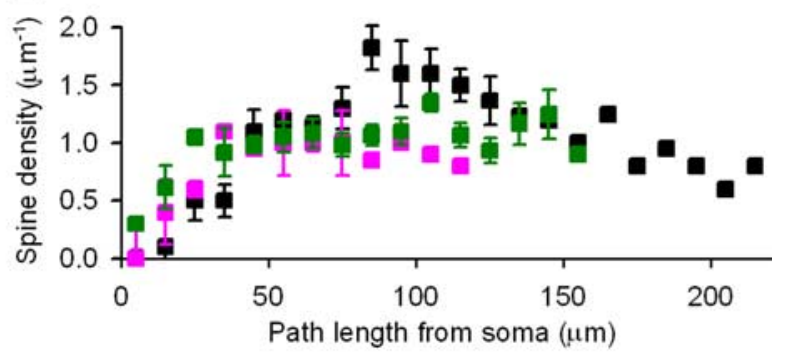

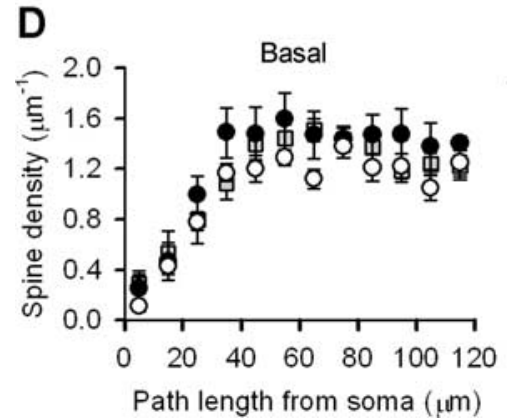

E

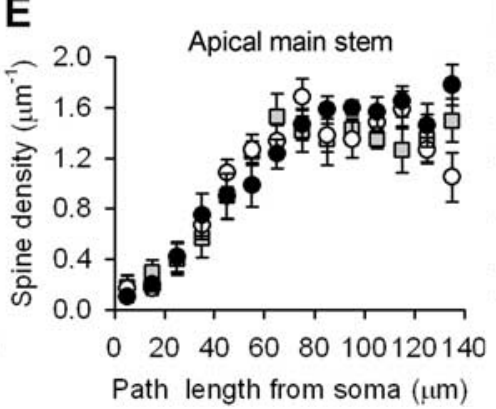

$\mathbf{F}$

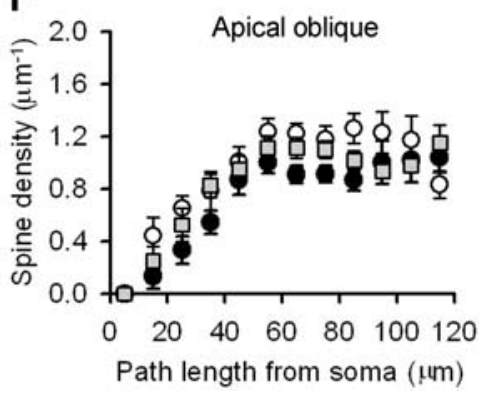

Figure 2. Dendritic spine density of $\mathrm{L} 2 / 3$ pyramidal neurons. $\boldsymbol{A}$, Maximum intensity projection of a deconvolved $z$-stack showing a $10 \mu \mathrm{m}$ section of dendrite. Scale bar, $2 \mu \mathrm{m}$. $\boldsymbol{B}$, Schematic illustrating sampled basal (magenta), apical oblique (green), and apical trunk plus terminal arbor (black) dendrites. $C$, Spine densities along the basal (magenta), apical oblique (green), and apical trunk plus terminal arbor (black) dendrites for an L2/3 pyramidal neuron in control cortex. D. Mean spine densities along basal dendrites of neurons in control (gray squares), deprived (white circles), and spared (black circles) cortex. $\boldsymbol{E}$, Mean spine densities along the apical main stem of neurons in control (gray squares), deprived (white circles), and spared (black circles) cortex. $\boldsymbol{F}$, Mean spine densities along apical oblique dendrites of neurons in control (gray squares), deprived (white circles), and spared (black circles) cortex. Error bars in $\mathbf{D}-\boldsymbol{F}$ represent SEM.

\section{Spine density on apical dendrites}

We next asked whether spine density on apical dendrites paralleled the changes that we found on basal dendrites. Spine density along apical dendrites varied with distance from the soma and tended to be greater along the apical main stem (peak spine density per neuron on the apical main stem averaged over $80-100$ $\mu \mathrm{m}$ from soma: control, $1.38 \pm 0.10$ spines $\cdot \mu \mathrm{m}^{-1}$ from 8 neurons; spared, $1.51 \pm 0.09$ spines $\cdot \mu \mathrm{m}^{-1}$ from 9 neurons; deprived, $1.43 \pm 0.09$ spines $\cdot \mu \mathrm{m}^{-1}$ from 9 neurons) (Fig. $2 E, F$ ). L2/3 pyramidal neurons, typically, have one apical main stem and, therefore, determining changes in apical spine density required a different sampling strategy to that used for basal dendrites (see Materials and Methods). We analyzed spine density on the apical main stem using deprivation status, age, and a smooth function of path length from the soma as explanatory variables (Table 2, model 8; supplemental Fig. 5, available at www.jneurosci.org as supplemental material). Spine density along the apical main stem was not changed in spared $(p=0.817)$ or deprived $(p=0.981)$ cortex compared with controls. Model 8 predicted that spine density on the apical main stem decreased with age by $7 \%$ in control cortex (P33, 1.41 spines $\cdot \mu \mathrm{m}$; $\mathrm{P} 49,1.31$ spines $\mu \mathrm{m})$, which is less than the predicted $12 \%$ reduction in peak basal spine density over the same period (see above, Spine density on basal dendrites, model 5). However, the decrease in apical spine density with age did not attain statistical significance $(p=0.066)$.

\section{Regions of proximity}

Our analyses revealed only low-level structural alterations in dendritic trees of L2/3 pyramidal neurons after weeks of whisker deprivation. Remodeling was mainly restricted to deprived cortex and, hence, appears insufficient to explain how previous experience might accelerate experience-dependent plasticity in spared cortex. Axonal wiring is an alternative candidate locus. Axonal remodeling was quantified by studying sites where syn- apses could be formed between pairs of $\mathrm{L} 2 / 3$ pyramidal neurons (Fig. 3A, supplemental Fig. 6, available at www.jneurosci.org as supplemental material) that were known from electrophysiological recordings to be synaptically connected or unconnected. The majority of excitatory synapses onto L2/3 pyramidal neurons comprise axonal varicosities apposed to dendritic spines (Elhanany and White, 1990). Spine neck length varies with cortical region (Benavides-Piccione et al., 2002) and may change along the dendritic tree (Jones and Powell, 1969). Therefore, we measured how far the heads of dendritic spines extended from the dendritic shaft of L2/3 pyramidal neurons to establish a cylindrical zone around the dendritic shaft within which synapse formation could occur (Swindale, 1981; Stepanyants et al., 2002). The distance from a spine head to its dendritic shaft, i.e., the radius of the cylinder, was measured as the shortest distance from the middle of the spine head to the middle of the dendritic shaft. We refer to this distance as the spine neurogeometric radius (NGR).

The spine neurogeometric radius had a skewed normal distribution with a median of $1.41 \mu \mathrm{m}$ (IQR, 1.05-1.81 $\mu \mathrm{m}, n=598$ spines from 15 neurons) (Fig. $3 B$ ). Spines on apical or basal dendrites had similar neurogeometric radii [median (IQR): apical, 1.41 (1.07-1.85) $\mu \mathrm{m}, n=258$; basal, 1.40 (1.04-1.78) $\mu \mathrm{m}, n=$ $340 ; p=0.686$, Mann-Whitney rank sum test], but spine neurogeometric radius tended to increase with dendritic shaft diameter $(r=+0.44, p<0.001, n=135)$ (Fig. 3C). Spine neurogeometric radius was not affected by deprivation status [control, 1.45 (1.09-1.81) $\mu \mathrm{m}, n=247$ spines; spared, $1.40(1.04-1.82) \mu \mathrm{m}$, $n=351 ; p=0.632$, Mann-Whitney rank sum test].

For simplicity, we defined a uniform spine neurogeometric radius of $3 \mu \mathrm{m}$, which encompasses $\sim 98 \%$ of all spine heads (Fig. $3 B$ ). An RoP (Fig. $3 A$ ) was defined to occur when an axon of one pyramidal neuron was within $3 \mu \mathrm{m}$ of the center of a dendrite of the second pyramidal neuron, indicating that one or more synapses could be formed between the neurons. This definition does 
Ai
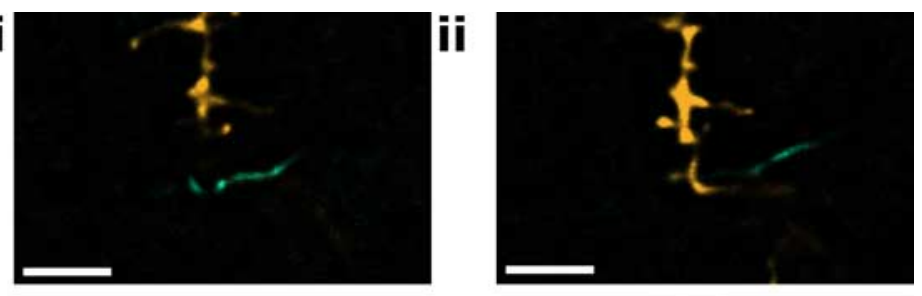

iii
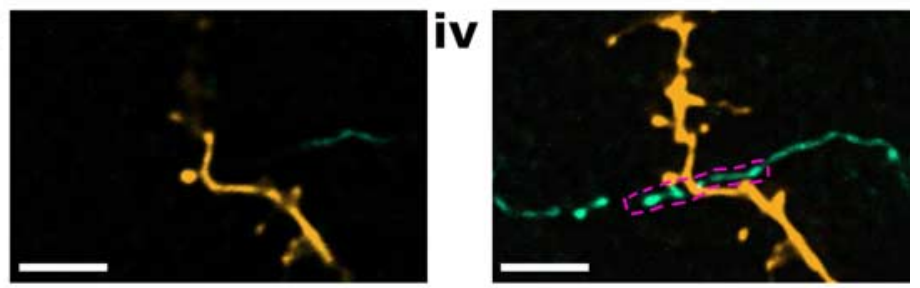

B

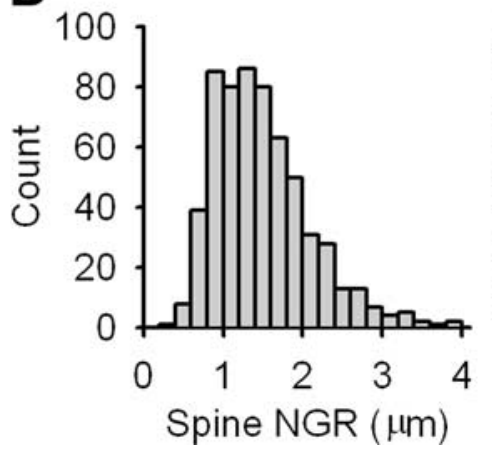

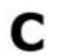

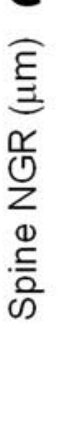

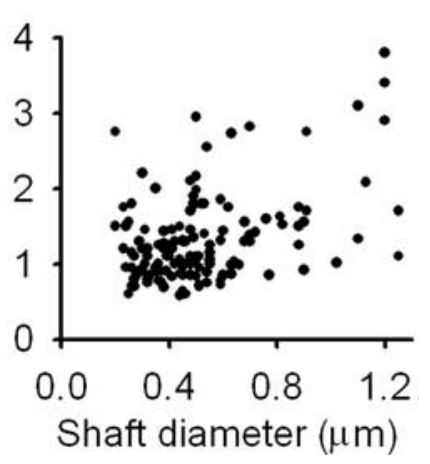

Figure 3. $\mathrm{L} 2 / 3$ pyramidal neurons have a spine neurogeometric radius of $3 \mu \mathrm{m}$. Ai-Aiii, Optical slices ( $0.8 \mu \mathrm{m}$ separation) through a region of proximity between the axon (green) of an $L 2 / 3$ pyramidal neuron and a dendrite (orange) of a second $L 2 / 3$ pyramidal neuron. The shortest distance between axon and dendrite is $0.8 \mu \mathrm{m}$. Electrophysiological recording showed that the pyramidal neurons were not synaptically connected. Aiv, Maximum intensity projection (three dimensional structure collapsed into two dimensions) of the region of proximity shown in $\mathbf{A i - A i i i . ~ M a g e n t a ~ d a s h e d ~ l i n e s ~ e n c l o s e ~ t h e ~ r e g i o n ~ o f ~ g r e e n ~ a x o n ~ t h a t ~ l i e s ~}$ within $3 \mu \mathrm{m}$ of the center of the orange dendrite in a three-dimensional reconstructed image. Scale bars, $3 \mu \mathrm{m}$. $\boldsymbol{B}$, Histogram of the NGR of dendritic spines on L2/3 pyramidal neurons. $C$, Relationship between spine NGR and the diameter of the dendritic shaft from which the spine emerges.

not require that a synapse be present in an RoP or that the pair of neurons be synaptically connected. The existence of a connection was determined from our electrophysiological recordings of each pair of L2/3 pyramidal neurons (Fig. $4 A, B$ ). Axonal remodeling was then analyzed using RoPs with data subdivided into groups depending on whether neurons were in control or spared cortex and the presence or absence of a synaptic connection between pairs of neurons. The presence of a putative synapse in an RoP was determined using the criteria for high-resolution confocal images that we reported recently (Cheetham et al., 2007).

\section{Axon length in RoPs is a poor predictor of local excitatory connectivity and synapse number}

Many studies of neocortical circuitry based on reconstructions of single neurons have used a working hypothesis commonly termed "Peters' rule," which states that the probability of synapse formation between an axon and a dendrite depends on the length of axon close to the dendrite (Peters and Feldman, 1976; Braitenberg and Schüz, 1998; Hellwig, 2000; Kalisman et al., 2003; Binzegger et al., 2004; Shepherd et al., 2005). This hypothesis can be tested directly with our data because we have recorded and reconstructed both connected and unconnected pairs of L2/3 pyramidal neurons. The hypothesis predicts that connected pairs of L2/3 pyramidal neurons should have either more RoPs or a greater total length of axon in RoPs than unconnected pairs of
L2/3 pyramidal neurons. However, we found that the number of RoPs between connected and unconnected pairs of L2/3 pyramidal neurons was similar in control cortex (connected, $3.8 \pm 0.8$ RoPs, $n=9$; unconnected, $3.6 \pm 1.2$ RoPs, $n=12$; $p=$ $0.899, t$ test) (Fig. $4 A-C$ ). Similarly, the total length of axon in RoPs was not different for connected and unconnected pairs of neurons in control cortex [connected, 28 (14-44) $\mu \mathrm{m}, n=9$; unconnected, 21 (9-33) $\mu \mathrm{m}, n=12$; $p=0.241$, MannWhitney rank sum test] (Fig. 4D). The majority (11 of 12) of unconnected pairs of L2/3 pyramidal neurons in control cortex had a least one RoP. For control pairs of connected and unconnected neurons with at least one $\operatorname{RoP}(n=20), 61 \pm 9 \%$ of RoPs were formed with basal dendrites and $39 \pm$ $9 \%$ of RoPs were formed with apical dendrites suggesting that RoPs were distributed over the dendritic tree. We drew two related conclusions from our analysis. First, our data show that the probability that a pair of pyramidal neurons is synaptically connected is not tightly related to the length of axon close to dendrite. Second, our results demonstrate that $\mathrm{L} 2 / 3$ pyramidal neurons have the potential, i.e., axon within a spine neurogeometric radii of a postsynaptic dendrite, to form synapses with the vast majority of neighboring pyramidal neurons, as reported for L5 pyramidal neurons (Kalisman et al., 2005).

Although length of axon close to dendrite does not determine the probability of forming a connection, it remains possible that it regulates synapse number at established connections. However, we found that synapse number was only weakly related to total length of axon in RoPs for connected pairs of L2/3 pyramidal neurons in control cortex (supplemental text, Synapse number and length of axon close to postsynaptic dendrite, available at www.jneurosci.org as supplemental material). We concluded that total length of axon in RoPs is a poor predictor of the number of synapses formed at local excitatory connections by L2/3 pyramidal neurons.

\section{Whisker deprivation modifies regions of proximity}

We next examined whether altered sensory experience modified RoPs. The number of RoPs between unconnected L2/3 pyramidal neurons in spared cortex $(2.9 \pm 0.5$ RoPs/axon, $n=9$ axons; $p=$ $0.512, t$ test $)$ was similar to controls $(3.7 \pm 0.7$ RoPs/axon, $n=21$ axons). However, the number of RoPs between connected pairs of L2/3 pyramidal neurons in spared cortex [median (IQR): 9 (5-12) RoPs/axon, $n=11$ axons; $p=0.001$, Mann-Whitney rank sum test] was larger than controls [3 (1-5) RoPs/axon, $n=$ 21 axons]. The presence of a synaptic connection did not affect the mean length of axon in an RoP for control (control connected, $10.1 \pm 1.8 \mu \mathrm{m}$ axon/RoP, $n=9$ axons; control unconnected, $7.5 \pm 1.0 \mu \mathrm{m}$ axon/RoP, $n=12$ axons; $p=0.193, t$ test) or spared (spared connected, $9.1 \pm 0.6 \mu \mathrm{m}$ axon/RoP, $n=11$ axons; spared unconnected, $8.0 \pm 1.1 \mu \mathrm{m}$ axon/RoP, $n=8$ axons; $p=0.329, t$ test) pairs of L2/3 pyramidal neurons. The total 


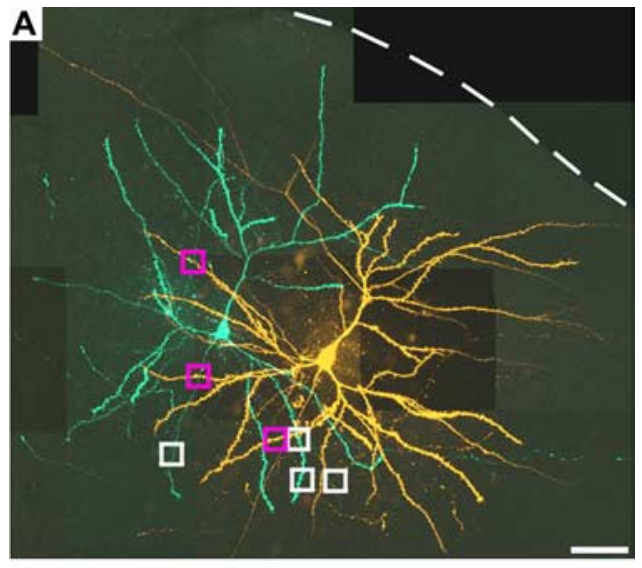

B

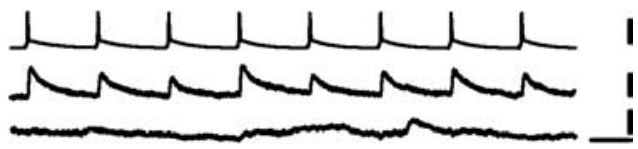

C

D
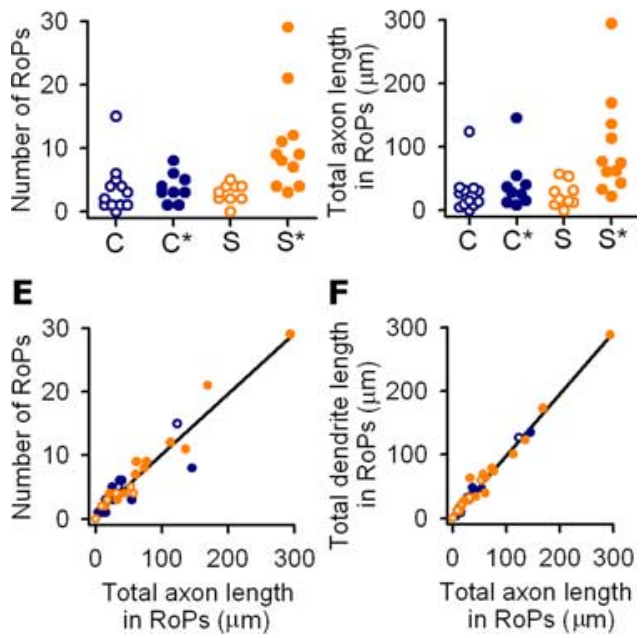

Figure 4. Connected neurons in spared cortex have more regions of proximity. A, Montage of maximum intensity projections of confocal $z$-stacks of a pair of unconnected $L 2 / 3$ pyramidal neurons in control cortex. The white dashed line denotes the pia. White boxes (not to scale) indicate the sites of RoPs formed by the axon of the orange neuron; magenta boxes denote the sites of RoPs formed by the axon of the green neuron. Scale bar, $40 \mu \mathrm{m}$. B. Electrophysiological recordings showing stimulation of the presynaptic neuron to fire a train of eight action potentials (top trace), unitary EPSPs in a postsynaptic neuron (middle trace), and the absence of responses in an unconnected neuron (bottom trace). Traces are an average of 10 consecutive sweeps. Only one train of presynaptic action potentials is shown to avoid repetition. Calibrations: (top to bottom) 60, 0.4, and $0.4 \mathrm{mV} ; 25 \mathrm{~ms}$. C, Number of RoPs formed by unconnected neurons in control cortex ( $C$; unfilled blue circles; $n=12)$, connected neurons in control cortex ( ${ }^{*}$; filled blue circles; $\left.n=9\right)$, unconnected neurons in spared cortex (S; unfilled orange circles; $n=9$ ), and connected neurons in spared cortex ( $\boldsymbol{S}^{*}$; filled orange circles; $\left.n=11\right)$. D , Total axon length in RoPs for neurons (groups are as in $\boldsymbol{C}$. $\boldsymbol{E}$, Relationship between total axon length in RoPs and number of RoPs for pairs of L2/3 pyramidal neurons in control and spared cortex. Colors are as in $\boldsymbol{C}$. The black line is a linear regression fit for all data points. $\boldsymbol{F}$, Relationship between total axon length in RoPs and total dendrite length in RoPs for pairs of pyramidal neurons in control and spared cortex. Colors are as in $\boldsymbol{C}$. The black line is the linear regression fit for all data points.

length of axon within RoPs was linearly related to the number of RoPs (Fig. $4 E$ ) ( $r=0.95, p<0.001$, Pearson's product correlation) and to the length of dendrite within those RoPs (Fig. $4 F$ ) ( $r=0.99, p<0.001$, Pearson's product correlation). Therefore, we characterized RoPs between each pair of neurons by their total axonal length (Table 2, model 9). Data from pairs of spared L2/3 pyramidal neurons were further subdivided into connected and unconnected subgroups. The total length of axon in RoPs between connected L2/3 pyramidal neurons in spared cortex ( $98 \pm$ $24 \mu \mathrm{m}$ per connection, $n=11$ axons, $p=0.004$ ) was three times greater than controls ( $33 \pm 8 \mu \mathrm{m}$ per connection, $n=21$ axons), whereas the total length of axon in RoPs between unconnected $\mathrm{L} 2 / 3$ pyramidal neurons in spared cortex was similar to controls (25 $\pm 7 \mu \mathrm{m}$ per connection, $n=9$ axons, $p=0.482$ ). The intersomatic distance for pairs of $\mathrm{L} 2 / 3$ pyramidal neurons did not differ across groups (control unconnected, $79 \pm 9 \mu \mathrm{m}, n=12$ pairs; control connected, $54 \pm 7 \mu \mathrm{m}, n=9$ pairs; spared unconnected, $73 \pm 9 \mu \mathrm{m}, n=9$ pairs; spared connected, $70 \pm 9 \mu \mathrm{m}$, $n=11$ pairs; $p=0.252, F_{(3,37)}=1.42$, one-way ANOVA) (supplemental Fig. 7, available at www.jneurosci.org as supplemental material). Hence, whisker trimming did not cause generalized axonal growth in spared cortex, but instead induced axonal remodeling that targeted existing connections between spared L2/3 pyramidal neurons.

We assessed whether whisker deprivation modified the spatial location and distribution of RoPs. Whisker trimming did not alter the mean distance of RoPs from the soma (control unconnected, $99 \pm 11 \mu \mathrm{m}, n=11$ pairs; control connected, $75 \pm 10$ $\mu \mathrm{m}, n=9$ pairs; spared unconnected, $80 \pm 10 \mu \mathrm{m}, n=8$ pairs; spared connected, $84 \pm 9 \mu \mathrm{m}, n=11$ pairs; $p=0.345, F_{(3,35)}=$ 1.14 , one-way ANOVA). Hence, the increased number of RoPs between synaptically connected L2/3 pyramidal neurons in spared cortex could not be attributed to preferential formation of RoPs on either distal or proximal dendrites. The proportion of RoPs on basal dendrites did not change after whisker trimming (control unconnected, $47 \pm 14 \%, n=11$ axons; control connected, $78 \pm 7 \%, n=9$ axons; spared unconnected, $61 \pm 17 \%$, $n=8$ axons; spared connected, $62 \pm 9 \%, n=11$ axons; $p=$ $0.358, F_{(3,35)}=1.11$, one-way ANOVA), suggesting that the distribution of RoPs on dendritic trees was not affected by whisker trimming. The majority of dendrites that formed RoPs with any given axon formed only one RoP per dendritic segment (one RoP per segment, 90.5\%; two RoPs per segment, 8\%; three RoPs per segment, $1.5 \% ; n=222$ RoPs in 200 dendritic segments from 21 control neurons and 20 spared neurons). We found three occurrences of three RoPs per dendritic segment (one unconnected pair of control L2/3 pyramidal neurons and two connected pairs of spared L2/3 pyramidal neurons). Connected pairs of L2/3 pyramidal neurons in spared cortex did not show increased numbers of dendritic segments with more than one RoP compared with control connected ( $p=0.419, \chi^{2}$ test), control unconnected ( $p=0.914, \chi^{2}$ test), or spared unconnected $(p=0.402$, $\chi^{2}$ test) pairs of L2/3 pyramidal neurons (number of segments with more than one RoP per total segments: spared connected, 10/107; control connected, 1/33; control unconnected, 4/38; spared unconnected, 4/22). Therefore, the increased number of RoPs between connected pairs of L2/3 pyramidal neurons in spared cortex could not be attributed to the presence of multiple RoPs close together because of an axon leaving an RoP and forming a separate RoP a short distance along the same dendrite. We concluded that RoPs between L2/3 pyramidal neurons in spared cortex were not tightly clustered on the postsynaptic dendritic tree, but were usually formed on different dendritic segments.

\section{Whisker deprivation alters axonal varicosity density}

We next asked whether experience-dependent plasticity altered axonal varicosities (Fig. 5A-F). Varicosity density in spared cortex was increased compared with control cortex (raw data for all ages: control, $0.80 \pm 0.03$ varicosities/ $\mu \mathrm{m}$ axon; spared, $0.93 \pm$ 


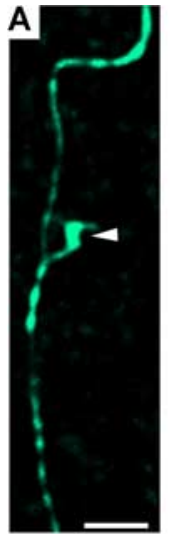

E

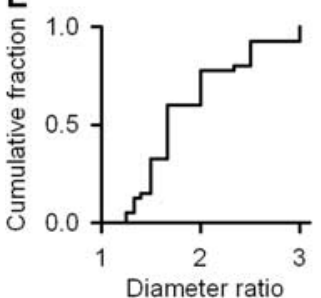

G

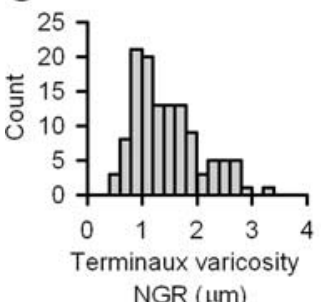

NGR $(\mu \mathrm{m})$
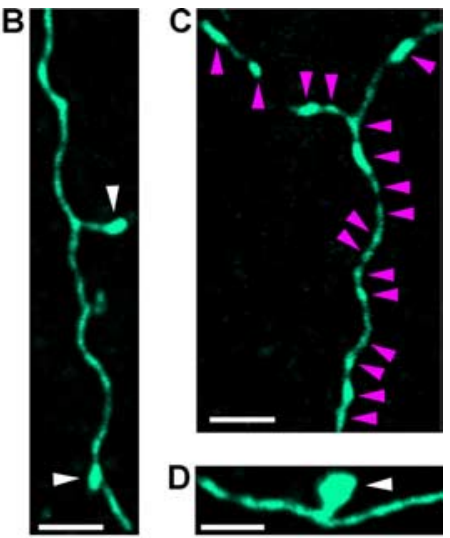

F

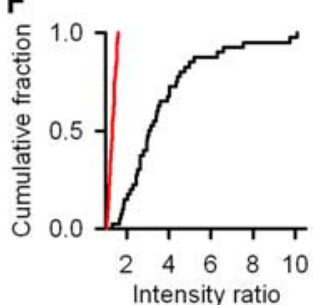

H

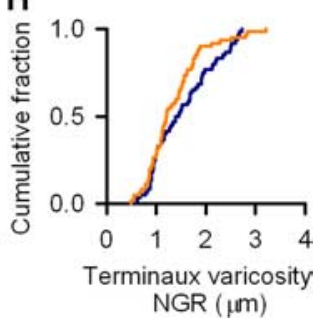

Figure 5. Axonal varicosities. $A-D$, Maximum intensity projections of sections of $L 2 / 3$ pyramidal neuron axons. The white arrowheads in $\boldsymbol{A}, \boldsymbol{B}$, and $\boldsymbol{D}$ indicate terminaux varicosities. Magenta arrowheads in Cindicate en passant varicosities. Scale bars, $2 \mu \mathrm{m}$. E, Empirical distribution function of the diameter ratio for regions of axon that are wider than adjacent axonal shaft in the plane of the optical section. $\boldsymbol{F}$, Empirical distribution function of the intensity ratio for axon that is expanded compared with adjacent axonal shaft in the plane of the confocal optical section (black line, $n=40$ ) and for axon that increases in intensity, but remains the same diameter as adjacent axonal shaft (red line, $n=40$ ). $\mathbf{G}$, Histogram of terminaux varicosity neurogeometric radius pooled from spared and control cortex. The neurogeometric radii of terminaux varicosities were not different from the neurogeometric radii of spines in Figure $3 B$ ( $p=0.190$, Kolmogorov-Smirnov test). $\boldsymbol{H}$, Empirical distribution function of terminaux varicosity NGR in spared (orange) and control (blue) cortex. There was no difference in the distributions ( $p=0.103$, two-sample Kolmogorov-Smirnov test).

0.02 varicosities/ $\mu \mathrm{m}$ axon; $n=168$ axonal segments, 42 segments from 14 control axons, and 126 segments from 15 spared axons; $p=0.008$ ) (Table 2, model 10; supplemental Fig. 8, available at www.jneurosci.org as supplemental material). This suggests that axonal remodeling in spared cortex is associated with higher varicosity density (supplemental text, available at www. jneurosci.org as supplemental material).

Axonal varicosities are commonly divided into two types: en passant and terminaux (Fig. 5A-D). We examined whether the proportion of terminaux varicosities was modified by whisker deprivation (Table 2, model 11). The percentage of terminaux varicosities on $\mathrm{L} 2 / 3$ pyramidal axons that were connected ( $8.7 \pm$ $1.9 \%, n=15$ axon segments) or unconnected $(7.5 \pm 1.0 \%, n=$ 20 axon segments) to a second $\mathrm{L} 2 / 3$ pyramidal neuron in control cortex were similar ( $p=0.889$ ). In contrast, the proportion of terminaux varicosities on axons of $\mathrm{L} 2 / 3$ pyramidal neuron in spared cortex was increased (connected, $10.6 \pm 0.7 \%, n=52$ axon segments, $p=0.038$; unconnected pairs, $12.5 \pm 0.5 \%, n=$ 11 axon segments, $p<0.001)$ compared with control connected pairs. The neurogeometric radii of terminaux varicosities in spared and control cortex were similar [spared, 1.45 (0.98-1.96) $\mu \mathrm{m}$; control, $1.21(0.94-1.63) \mu \mathrm{m} ; n=60$ varicosities from 5 axons for each group; $p=0.129$, Mann-Whitney rank sum test] (Fig. 5G,H). These findings indicate that whisker deprivation increased the density of terminaux varicosities on axons of L2/3 pyramidal neurons in spared cortex.

\section{Discussion}

The major new finding in this study is that experience-dependent plasticity induced by whisker trimming resulted in targeted remodeling of the axonal arbors linking synaptically connected pairs of L2/3 pyramidal neurons in spared cortex. The remodeling increased the length of axon in RoPs. In contrast, whisker deprivation induced only minor modifications in the dendritic structure of L2/3 pyramidal neurons.

\section{Remodeled axon in spared cortex}

Our data show that whisker trimming caused axonal remodeling in spared cortex. The remodeling resulted in a greater number of regions of proximity between synaptically connected L $2 / 3$ pyramidal neurons (Fig. $2 F$ ) combined with a higher density of terminaux varicosities on the axons of $\mathrm{L} 2 / 3$ pyramidal neurons in spared cortex. The ability of axons to grow and retract varies with age and neuron type (Luo and O'Leary, 2005; Portera-Cailliau et al., 2005; De Paola et al., 2006) and has not been fully characterized for L2/3 pyramidal neurons. However, prolonged monocular deprivation up to P60 causes remodeling of thalamocortical axons in mouse visual cortex (Antonini et al., 1999) and suggests that axonal arbors in rodent neocortex can restructure during the second postnatal month at least.

Our RoP analysis revealed that L2/3 pyramidal neurons have the structural substrate (axon within a spine NGR of dendrite) for near all-to-all connectivity with other L2/3 pyramidal neurons within a barrel column. Therefore, expansion of axonal arbors (Darian-Smith and Gilbert, 1994; Florence et al., 1998; Knudsen, 1998; Kossut, 1998; Antonini et al., 1999; DeBello et al., 2001; Linkenhoker et al., 2005) is not necessary to enable new connections to be established within local excitatory microcircuits.

The length of axon in RoPs between unconnected pairs of L2/3 pyramidal neurons in spared cortex was not increased compared with RoPs between L2/3 pyramidal neurons in control cortex. Furthermore, local excitatory connectivity and synapse number per connection do not change in spared cortex after whisker trimming (Cheetham et al., 2007). Together, these findings suggest that the increase in number of RoPs between synaptically connected pairs of L2/3 pyramidal neurons in spared cortex is unlikely to be explained by a generalized increase in axonal elaboration. Instead, our data indicate that axonal remodeling is targeted specifically within spared cortex.

We found that there was a small, but significant increase in varicosity density on the axons of spared L2/3 pyramidal neurons. Not all varicosities are presynaptic boutons, i.e., have presynaptic vesicles adjacent to an active zone (Shepherd and Harris, 1998; White et al., 2004). Our varicosity criteria avoid excluding small varicosities that are presynaptic boutons. The expansion of the axon shaft that we require to score a structure as a varicosity is less than that mandated by some electron microscopy studies (Shepherd and Harris, 1998). Hence, our data may include a higher proportion of small varicosities that do not form synapses. However, it is unclear whether many of these small axonal vari- 
cosities represent a residual expansion in the axonal shaft signifying that a synapse was present previously and has disassembled, a nascent axonal bouton, or arise from natural variations in axonal shaft diameter. Confocal microscopy followed by serial section electron microscopy would be needed to resolve these issues. However, synapse number at local excitatory connections in L2/3 of spared cortex is unchanged (Cheetham et al., 2007). Therefore, we view the increased varicosity density and greater number of terminaux varicosities as indicators of fine-scale changes in the structure of excitatory axons of L2/3 pyramidal neurons in spared cortex. The apparent inconsistency between increased bouton density and decreased dendritic spine density on L2/3 pyramidal neurons may be attributable to L2/3 pyramidal neuron axons forming more synapses with interneurons or L5 pyramidal neuron dendrites.

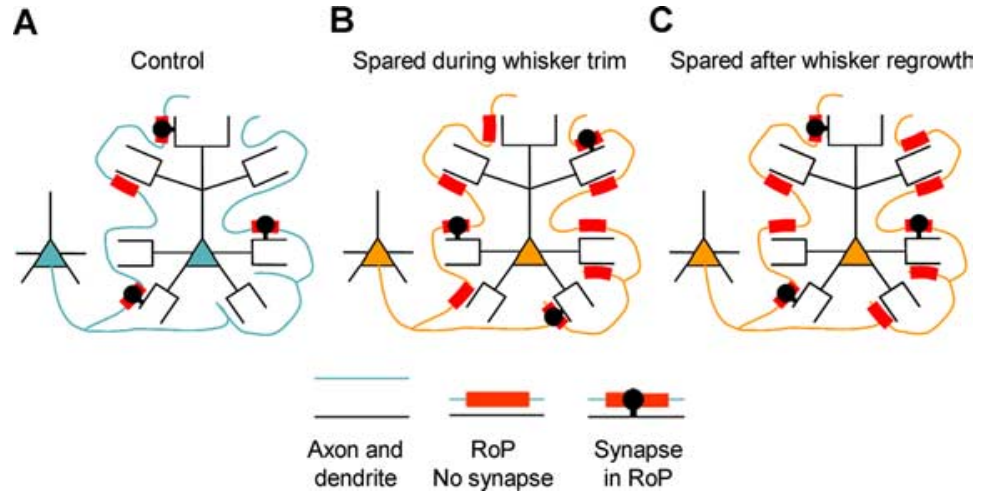

Figure 6. Model of how previous experience could accelerate experience-dependent plasticity in adulthood. $\boldsymbol{A}, \mathrm{Sch}$ ematic of a pair of L2/3 pyramidal neurons (blue somata) in control cortex. The axon (blue) of the presynaptic neuron synapses with the dendrites (black) of the neighboring L2/3 pyramidal neuron. An axon in a region of proximity is indicated by a thickened red bar. Synapses are denoted by spines from the dendritic tree contacting red axon. $\boldsymbol{B}$, Schematic showing the axon (orange) of a presynaptic $L 2 / 3$ pyramidal neuron synapsing with the dendrites of a neighboring $L 2 / 3$ pyramidal neuron in spared cortex after whisker trimming and before whiskers have regrown. Regions of proximity and synapses are coded as in $\boldsymbol{A}$. For emphasis, the sites of all synapses have been changed. $\boldsymbol{C}$, Hypothesized relocation of the sites of synapses onto L2/3 pyramidal neurons in spared cortex after whiskers are allowed to regrow. The sites of synapses in spared cortex after whisker trimming schematized in $\boldsymbol{B}$ revert to the control, untrimmed state shown in $\boldsymbol{A}$ after whiskers have been allowed to regrow. The regions of proximity are unchanged. For simplicity, the figure key shows only the control (blue) axon but also applies to the spared (orange) axon.

\section{Dendrites do not exhibit large-scale remodeling after whisker trimming}

Dendritic remodeling has been reported after sensory enrichment in adult rats (Uylings et al., 1978). However, our analysis found no evidence for large-scale dendritic changes attributable to whisker trimming. Our findings are consistent with imaging studies, which report that the dendritic trees of excitatory neurons in adult cortex are broadly stable over weeks (Trachtenberg et al., 2002; Mizrahi and Katz, 2003; Lee et al., 2006). We found a slight shortening of basal dendrites in deprived cortex, which is minor compared with the large-scale dendritic remodeling described after deafferentation (Hickmott and Steen, 2005; Tailby et al., 2005). The difference may be because deafferentation induces a more complete form of deprivation. Alternatively, deafferentation may invoke different plasticity mechanisms from those that are activated when the nervous system is intact.

\section{Differential effect of whisker trimming on spine density}

The effects of whisker trimming on spine density in mature rodents have been debated (Trachtenberg et al., 2002; Zuo et al., 2005b; Xu et al., 2007). We found decreased basal spine density and slightly shorter terminal segments of basal dendrites (equivalent to the loss of a few spine lengths) on deprived L2/3 pyramidal neurons that were attributable to whisker trimming. These changes were superimposed on the normal age-related decrease in spine density during the second postnatal month that has been reported previously (Wise et al., 1979; Markus and Petit, 1987). Hence, there was a subtle but generalized retrenchment of basal dendrites on L2/3 pyramidal neurons in deprived cortex. We cannot completely exclude the possibility that whisker trimming induces a small acceleration of spine loss on basal dendrites of L2/3 pyramidal neurons in spared cortex.

Our analysis indicated that apical spine density was not clearly affected by whisker trimming. Miniature EPSP frequency in L2/3 pyramidal neurons decreases over our study period (Cheetham et al., 2007) (supplemental text, available at www.jneurosci.org as supplemental material) and imaging studies have reported that spine density on apical dendrites of layer 5 pyramidal neurons (Zuo et al., 2005a; Majewska et al., 2006) and L2/3 pyramidal neurons (Majewska et al., 2006) decreases with age. Thus, both basal and apical spine density on L2/3 pyramidal neurons may decrease between P33 and P49, but the decrease in spine density may be slower on the apical main stem compared with basal dendrites, making it more difficult to detect.

The acceleration of spine loss on basal dendrites in deprived cortex by our whisker trimming protocol appears to differ from the findings after a chessboard whisker trim, which reported reduced spine elimination from apical dendrites of L5 pyramidal neurons (Zuo et al., 2005b). However, deprivation-induced changes in spine number/density may be cell-type specific (Holtmaat et al., 2006). Hence, the apparent discrepancy is probably attributable to the different neuron types studied.

\section{Axonal rewiring can explain the acceleration of experience-dependent plasticity}

Many studies of the neurogeometry of neocortical circuitry (Braitenberg and Schüz, 1998; Hellwig, 2000; Kalisman et al., 2003; Binzegger et al., 2004; Shepherd et al., 2005) have assumed that the probability of synapse formation is directly related to the physical opportunity for synapse formation, e.g., the length of axon in RoPs. Our data show that this assumption does not apply to local excitatory connections in supragranular somatosensory cortex. Why then do axonal arbors remodel to increase axon length in RoPs between synaptically connected pairs of L2/3 pyramidal neurons if not to increase synapse number or local excitatory connectivity? It has been proposed that previous experience accelerates perceptual learning and experience-dependent plasticity in adulthood by leaving a trace in primary sensory neocortex, which carries a memory of this previous experience (Harris et al., 1999; Hofer et al., 2006). Perceptual learning using a subset of whiskers is transferred to untrained neighboring whiskers if deflection of the untrained whiskers evokes cortical response patterns similar to the cortical responses elicited by the trained whiskers (Harris et al., 1999). This suggests that axons of pyramidal neurons in primary somatosensory cortex harbor a memory trace of tactile-perceptual learning (Harris et al., 1999). The specificity of axonal remodeling that we describe after whisker trimming supports this hypothesis. 
A simple model based on our findings can explain how previous experience accelerates perceptual learning and experiencedependent plasticity in adult neocortex (Fig. 6). Axonal remodeling (Löwel and Singer, 1992; De Paola et al., 2006; Majewska et al., 2006; Stettler et al., 2006) is targeted toward neurons with which the axon is already connected (Fig. 6A,B). New axonal branches may arise from terminaux varicosities, which become stabilized and act as a source for axonal elaboration (Meyer and Smith, 2006; Stettler et al., 2006). Formation and elimination of axonal boutons (De Paola et al., 2006; Majewska et al., 2006; Stettler et al., 2006) and dendritic spines (Holtmaat et al., 2005; Zuo et al., 2005a) occur normally in adult cortex. Hence, the axonal remodeling permits new synapse formation (Knott et al., 2006) at different dendritic locations, thereby enabling modifications in the transmission properties of excitatory connections (Poirazi and Mel, 2001; Häusser and Mel, 2003; Froemke et al., 2005; Gordon et al., 2006). We propose that new synapses are formed in spared cortex with elimination of old synapses to keep synapse number per connection similar (Cheetham et al., 2007) and that this occurs without retraction of axon from the sites of the eliminated synapses. Thus, the unretracted axon represents an anatomical memory trace of previous sensory experience, which primes local excitatory microcircuits to revert to the pretrimmed state if the whiskers regrow (Fig. 6C). Restarting whisker deprivation in adulthood would cause local excitatory connections to rewire to their whisker-trimmed state. This could be effected rapidly because it does not require axonal growth.

\section{References}

Antonini A, Fagiolini M, Stryker MP (1999) Anatomical correlates of functional plasticity in mouse visual cortex. J Neurosci 19:4388-4406.

Benavides-Piccione R, Ballesteros-Yáñez I, DeFelipe J, Yuste R (2002) Cortical area and species differences in dendritic spine morphology. J Neurocytol 31:337-346.

Binzegger T, Douglas RJ, Martin KA (2004) A quantitative map of the circuit of cat primary visual cortex. J Neurosci 24:8441-8453.

Braitenberg V, Schüz A (1998) Cortex: statistics and geometry of neuronal connectivity. Berlin: Springer.

Buonomano DV, Merzenich MM (1998) Cortical plasticity: from synapses to maps. Annu Rev Neurosci 21:149-186.

Cheetham CE, Hammond MS, Edwards CE, Finnerty GT (2007) Sensory experience alters cortical connectivity and synaptic function site specifically. J Neurosci 27:3456-3465.

Chklovskii DB, Mel BW, Svoboda K (2004) Cortical rewiring and information storage. Nature 431:782-788.

Cochran WG (1977) Sampling techniques. New York: Wiley.

Dahmen JC, King AJ (2007) Learning to hear: plasticity of auditory cortical processing. Curr Opin Neurobiol 17:456-464.

Darian-Smith C, Gilbert CD (1994) Axonal sprouting accompanies functional reorganization in adult cat striate cortex. Nature 368:737-740.

DeBello WM, Feldman DE, Knudsen EI (2001) Adaptive axonal remodeling in the midbrain auditory space map. J Neurosci 21:3161-3174.

De Paola V, Holtmaat A, Knott G, Song S, Wilbrecht L, Caroni P, Svoboda K (2006) Cell type-specific structural plasticity of axonal branches and boutons in the adult neocortex. Neuron 49:861-875.

Diamond ME, Huang W, Ebner FF (1994) Laminar comparison of somatosensory cortical plasticity. Science 265:1885-1888.

Elhanany E, White EL (1990) Intrinsic circuitry: synapses involving the local axon collaterals of corticocortical projection neurons in the mouse primary somatosensory cortex. J Comp Neurol 291:43-54.

Florence SL, Taub HB, Kaas JH (1998) Large-scale sprouting of cortical connections after peripheral injury in adult macaque monkeys. Science 282:1117-1121.

Fox K (2002) Anatomical pathways and molecular mechanisms for plasticity in the barrel cortex. Neuroscience 111:799-814.

Froemke RC, Poo MM, Dan Y (2005) Spike-timing-dependent synaptic plasticity depends on dendritic location. Nature 434:221-225.
Gibson EJ (1953) Improvement in perceptual judgments as a function of controlled practice or training. Psychol Bull 50:401-431.

Gilbert CD, Sigman M, Crist RE (2001) The neural basis of perceptual learning. Neuron 31:681-697.

Glazewski S, Fox K (1996) Time course of experience-dependent synaptic potentiation and depression in barrel cortex of adolescent rats. J Neurophysiol 75:1714-1729.

Gordon U, Polsky A, Schiller J (2006) Plasticity compartments in basal dendrites of neocortical pyramidal neurons. J Neurosci 26:12717-12726.

Greenough WT (1984) Structural correlates of information storage in the mammalian brain: a review and hypothesis. Trends Neurosci 7:229-233.

Guić-Robles E, Valdivieso C, Guajardo G (1989) Rats can learn a roughness discrimination using only their vibrissal system. Behav Brain Res 31:285-289.

Harris JA, Petersen RS, Diamond ME (1999) Distribution of tactile learning and its neural basis. Proc Natl Acad Sci U S A 96:7587-7591.

Harris JA, Petersen RS, Diamond ME (2001) The cortical distribution of sensory memories. Neuron 30:315-318.

Hastie T, Tibshirani R (1990) Generalized additive models. London, UK: Chapman and Hall.

Häusser M, Mel B (2003) Dendrites: bug or feature? Curr Opin Neurobiol 13:372-383.

Hebb DO (1949) Organization of behavior: a neuropsychological theory. New York: Wiley.

Hellwig B (2000) A quantitative analysis of the local connectivity between pyramidal neurons in layers $2 / 3$ of the rat visual cortex. Biol Cybern 82:111-121.

Hickmott PW, Steen PA (2005) Large-scale changes in dendritic structure during reorganization of adult somatosensory cortex. Nat Neurosci 8:140-142.

Hofer SB, Mrsic-Flogel TD, Bonhoeffer T, Hübener M (2006) Prior experience enhances plasticity in adult visual cortex. Nat Neurosci 9:127-132.

Holtmaat A, Wilbrecht L, Knott GW, Welker E, Svoboda K (2006) Experience-dependent and cell-type-specific spine growth in the neocortex. Nature 441:979-983.

Holtmaat AJ, Trachtenberg JT, Wilbrecht L, Shepherd GM, Zhang XQ, Knott GW, Svoboda K (2005) Transient and persistent dendritic spines in the neocortex in vivo. Neuron 45:279-291.

Jones EG, Powell TP (1969) Morphological variations in the dendritic spines of the neocortex. J Cell Sci 5:509-529.

Kaas JH (1987) The organization of cortex in mammals: implications for theories of brain function. Annu Rev Psychol 38:124-151.

Kalisman N, Silberberg G, Markram H (2003) Deriving physical connectivity from neuronal morphology. Biol Cybern 88:210-218.

Kalisman N, Silberberg G, Markram H (2005) The neocortical microcircuit as a tabula rasa. Proc Natl Acad Sci U S A 102:880-885.

Karmarkar UR, Dan Y (2006) Experience-dependent plasticity in adult visual cortex. Neuron 52:577-585.

Kelly MK, Carvell GE, Kodger JM, Simons DJ (1999) Sensory loss by selected whisker removal produces immediate disinhibition in the somatosensory cortex of behaving rats. J Neurosci 19:9117-9125.

Knott GW, Holtmaat A, Wilbrecht L, Welker E, Svoboda K (2006) Spine growth precedes synapse formation in the adult neocortex in vivo. Nat Neurosci 9:1117-1124.

Knudsen EI (1998) Capacity for plasticity in the adult owl auditory system expanded by juvenile experience. Science 279:1531-1533.

Knutsen PM, Pietr M, Ahissar E (2006) Haptic object localization in the vibrissal system: behavior and performance. J Neurosci 26:8451-8464.

Kossut M (1998) Experience-dependent changes in function and anatomy of adult barrel cortex. Exp Brain Res 123:110-116.

Larkman AU (1991) Dendritic morphology of pyramidal neurones of the visual cortex of the rat: III. Spine distributions. J Comp Neurol 306:332-343.

Lebedev MA, Mirabella G, Erchova I, Diamond ME (2000) Experiencedependent plasticity of rat barrel cortex: redistribution of activity across barrel-columns. Cereb Cortex 10:23-31.

Lee WC, Huang H, Feng G, Sanes JR, Brown EN, So PT, Nedivi E (2006) Dynamic remodeling of dendritic arbors in GABAergic interneurons of adult visual cortex. PLoS Biol 4:e29.

Liang KY, Zeger SL (1986) Longitudinal data-analysis using generalized linear-models. Biometrika 73:13-22.

Linkenhoker BA, von der Ohe CG, Knudsen EI (2005) Anatomical traces of 
juvenile learning in the auditory system of adult barn owls. Nat Neurosci 8:93-98.

Löwel S, Singer W (1992) Selection of intrinsic horizontal connections in the visual cortex by correlated neuronal activity. Science 255:209-212.

Luo L, O'Leary DD (2005) Axon retraction and degeneration in development and disease. Annu Rev Neurosci 28:127-156.

Maier DL, Grieb GM, Stelzner DJ, McCasland JS (2003) Large-scale plasticity in barrel cortex following repeated whisker trimming in young adult hamsters. Exp Neurol 184:737-745.

Majewska AK, Newton JR, Sur M (2006) Remodeling of synaptic structure in sensory cortical areas in vivo. J Neurosci 26:3021-3029.

Maravall M, Koh IY, Lindquist WB, Svoboda K (2004) Experiencedependent changes in basal dendritic branching of layer $2 / 3$ pyramidal neurons during a critical period for developmental plasticity in rat barrel cortex. Cereb Cortex 14:655-664.

Markus EJ, Petit TL (1987) Neocortical synaptogenesis, aging, and behavior: life-span development in the motor sensory system of the rat. Expl Neurol 96:262-278.

McCullagh P, Nelder JA (1989) Generalized linear models. London: Chapman and Hall.

Meyer MP, Smith SJ (2006) Evidence from in vivo imaging that synaptogenesis guides the growth and branching of axonal arbors by two distinct mechanisms. J Neurosci 26:3604-3614.

Mizrahi A, Katz LC (2003) Dendritic stability in the adult olfactory bulb. Nat Neurosci 6:1201-1207.

Peters A, Feldman ML (1976) The projection of the lateral geniculate nucleus to area 17 of the rat cerebral cortex. I. General description. J Neurocytol 5:63-84.

Poirazi P, Mel BW (2001) Impact of active dendrites and structural plasticity on the memory capacity of neural tissue. Neuron 29:779-796.

Polley DB, Chen-Bee CH, Frostig RD (1999) Two directions of plasticity in sensory-deprived adult cortex. Neuron 24:623-637.

Portera-Cailliau C, Weimer RM, De Paola V, Caroni P, Svoboda K (2005) Diverse modes of axon elaboration in the developing neocortex. PLoS Biol 3:e272.

Recanzone GH, Merzenich MM, Jenkins WM, Grajski KA, Dinse HR (1992) Topographic reorganization of the hand representation in cortical area $3 \mathrm{~b}$ owl monkeys trained in a frequency-discrimination task. J Neurophysiol 67:1031-1056.

Shepherd GM, Harris KM (1998) Three-dimensional structure and composition of CA3 $\rightarrow$ CA1 axons in rat hippocampal slices: Implications for presynaptic connectivity and compartmentalization. J Neurosci 18:8300-8310.
Shepherd GM, Stepanyants A, Bureau I, Chklovskii D, Svoboda K (2005) Geometric and functional organization of cortical circuits. Nat Neurosci 8:782-790

Stepanyants A, Hof PR, Chklovskii DB (2002) Geometry and structural plasticity of synaptic connectivity. Neuron 34:275-288.

Stern EA, Maravall M, Svoboda K (2001) Rapid development and plasticity of layer 2/3 maps in rat barrel cortex in vivo. Neuron 31:305-315.

Stettler DD, Yamahachi H, Li W, Denk W, Gilbert CD (2006) Axons and synaptic boutons are highly dynamic in adult visual cortex. Neuron 49:877-887.

Swindale NV (1981) Dendritic spines only connect. Trends Neurosci 4:240-241.

Tailby C, Wright LL, Metha AB, Calford MB (2005) Activity-dependent maintenance and growth of dendrites in adult cortex. Proc Natl Acad Sci U S A 102:4631-4636.

Trachtenberg JT, Chen BE, Knott GW, Feng G, Sanes JR, Welker E, Svoboda $\mathrm{K}$ (2002) Long-term in vivo imaging of experience-dependent synaptic plasticity in adult cortex. Nature 420:788-794.

Tsodyks M, Gilbert C (2004) Neural networks and perceptual learning. Nature 431:775-781.

Uylings HB, Kuypers K, Diamond MC, Veltman WA (1978) Effects of differential environments on plasticity of dendrites of cortical pyramidal neurons in adult rats. Exp Neurol 62:658-677.

Wallace H, Fox K (1999) The effect of vibrissa deprivation pattern on the form of plasticity induced in rat barrel cortex. Somatosens Mot Res $16: 122-138$.

White EL, Weinfeld E, Lev DL (2004) Quantitative analysis of synaptic distribution along thalamocortical axons in adult mouse barrels. J Comp Neurol 479:56-69.

Wise SP, Fleshman JW Jr, Jones EG (1979) Maturation of pyramidal cell form in relation to developing afferent and efferent connections of rat somatic sensory cortex. Neuroscience 4:1275-1297.

Xu HT, Pan F, Yang G, Gan WB (2007) Choice of cranial window type for in vivo imaging affects dendritic spine turnover in the cortex. Nat Neurosci 10:549-551.

Zeger SL, Liang KY (1986) Longitudinal data analysis for discrete and continuous outcomes. Biometrics 42:121-130.

Zuo Y, Lin A, Chang P, Gan WB (2005a) Development of long-term dendritic spine stability in diverse regions of cerebral cortex. Neuron 46:181-189.

Zuo Y, Yang G, Kwon E, Gan WB (2005b) Long-term sensory deprivation prevents dendritic spine loss in primary somatosensory cortex. Nature 436:261-265. 